\title{
Clinical testing of antiretroviral drugs as future prevention against vaginal and rectal transmission of HIV infection - a review of currently available results
}

\author{
JAKUB VYSLOUŽIL \\ KATEŘINA KUBOVÁ* \\ VERONIKA NOVÁKOVÁ TKADLEČKOVÁ \\ DAVID VETCHÝ \\ Department of Pharmaceutics \\ Faculty of Pharmacy \\ University of Veterinary and \\ Pharmaceutical Sciences Brno \\ Brno, Czech Republic
}

Accepted January 31, 2019

Published online March 6, 2019

\begin{abstract}
The original purpose of vaginally applied microbicides was to slow down the HIV epidemic among the population until an effective vaccination was developed. Nowadays, antiretrovirals applied in the form of gels or vaginal rings are considered most prominent in this field and are tested via vaginal or, rarely, rectal applications in numerous clinical studies (9 different antiretroviral drugs in 33 clinical studies, especially in Africa). Only tenofovir ( $1 \%$ gel) and dapivirine ( $25 \mathrm{mg}$ in vaginal ring) progressed into the phase III clinical testing. Their efficiency depended on the user's strict adherence to the application regimen (for tenofovir $54 \%$, for dapivirine $61 \%$ in participants over 25 years of age). Despite this, they are expected to be important and effective tools of preventive medicine in the near future. This review summarizes the results obtained during long-term clinical testing (2005-2018) of antiretroviral drugs against vaginal and rectal transmission of HIV infection.
\end{abstract}

Keywords: HIV prevention, microbicides, clinical trials, antiretroviral drugs

\section{INTRODUCTION}

The first case of HIV (human immunodeficiency virus)/AIDS (acquired immunodeficiency syndrome) was reported in 1980 and the prevalence has been rising since then (1). Currently, the numbers associated with this infection are more than alarming. Since the epidemic, the estimated cumulative number of HIV infections in the world to date is around 76 million people, of which more than 35 million have died. In 2016, according to the World Health Organization (WHO), 36.7 million people lived with the HIV diagnosis worldwide. In the same year, 1.8 million new infections occurred with 1.0 million people dying from AIDS-related illnesses, compared to 1.9 million in 2005 and 1.5 million in 2010. This continuous decrease in deaths can be explained by the massive use of expensive antiretroviral therapy. According to WHO, about 19.5 million patients were treated in 2016, which means that $53 \%$ of infected patients were treated. This is a major improvement over 2010 when approximately $23 \%$ of infected people were treated (2).

\footnotetext{
*Correspondence, e-mail address: kubovak@vfu.cz
} 
Microbicides are experimental products for the prevention of HIV sexual transmission, since none have been licensed yet. They are self-administered, vaginal or more recently rectal preparations intended for women, homosexuals and transgendered individuals as a protection against HIV transmission. The main purpose of their development had been to slow down the HIV epidemic. The original idea was to shorten the time required for the development of an effective vaccine. Even though more than 35 years have passed since the HIV virus was first identified, no vaccine is available yet. Hundreds of HIV-1 vaccine trials have been documented to date, but only six of those clinical trials included efficacy studies (3). For this reason, another form of effective prevention is extremely important because current prevention is based only on standard barrier protection during a sexual intercourse with a male or female condom. Especially in developing countries, cultural, political or legal factors often affect the ability of women to protect themselves from HIV. As a consequence, many women and girls often do not have the power to refrain from sex, or to persuade their partners to use condoms. From this point of view, prompt availability of microbicide products is pressing. On the other hand, willingness of the sexually active population to use such products is a huge factor in solving this problem.

Research of microbicides has proceeded for over twenty years (4). The funding to support this research has reached astronomical values, with cheaper microbicide candidates having completely failed, exhibiting no effectiveness. Only clinical trials of vaginal antiretroviral active pharmaceutical ingredients (APIs) have provided tangible evidence that this pathway may be beneficial. The aim of this review is to summarize the available information about clinical testing of antiretroviral APIs against vaginal and rectal transmission of HIV infection from 2005 to 2018.

\section{DEFINITION AND CLASSIFICATION OF MICROBICIDES AND THEIR MECHANISM OF ACTION}

Originally, the group of microbicides included substances from different pharmacological groups. Given that most of them were shown to be completely ineffective in clinical trials, the most promising APIs currently considered belong to the group of antivirals. The name "microbicides" was originally used for a group of APIs against different sexually transmitted diseases (mostly bacterial). Over time, the number of APIs, specifically against $\mathrm{HIV}$, was gradually increasing among them. In view of this fact, this designation is not entirely appropriate. According to the current concept, a microbicide can be defined as a chemical agent used in various topical (vaginal, rectal) application regimes that kills, neutralizes or blocks the HIV virus and other sexually transmitted pathogens, especially human papilloma virus (HPV), herpes simplex virus 2 (HSV-2) and others. Different dosage forms can be used for vaginal application, such as gels, creams, films, tablets or vaginal rings. As for rectal use, gels are considered to be the most preferable dosage form. The microbicide preparation is applied before and sometimes also after an intercourse, while the vaginal ring remains longer in the vaginal cavity.

Microbicides were formerly divided into two generations. The first-generation microbicides included non-specific and partially specific microbicides that were effective against a broader spectrum of sexually transmitted diseases, often with a spermicidal effect (5). The second-generation microbicides include specific microbicides that act only against HIV (6). Nowadays, this former division of microbicides into non-specific, partially spe- 
J. Vysloužil et al.: Clinical testing of antiretroviral drugs as future prevention against vaginal and rectal transmission of HIV infection - a review of currently available results, Acta Pharm. 69 (2019) 297-319.

Table I. List of antiretroviral candidates investigated as microbicides

\begin{tabular}{ll}
\hline Microbicide & Classification (mechanism of action) \\
\hline DS003 (BMS793) & $\begin{array}{l}\text { Entry inhibitor (It interferes with HIV infection by binding to protein } \\
\text { gp120 and prevents CD4 from inducing structural changes in gp120 which } \\
\text { drive the fusion protein gp41 to form six helix bundles and cause viral and } \\
\text { cellular membranes to fuse) (7) }\end{array}$ \\
\hline Emtricitabine & $\begin{array}{l}\text { Nucleoside reverse transcriptase inhibitor (It is a prodrug that must be } \\
\text { phosphorylated intracellularly into its active triphosphate form, emtricitabine } \\
5^{\prime} \text {-triphosphate, which is incorporated by reverse transcriptase into the } \\
\text { elongating proviral DNA chain leading to termination of DNA synthesis) (8) }\end{array}$ \\
\hline Maraviroc & $\begin{array}{l}\text { CCR5 antagonist (It exhibits an ability to bind to the chemokine receptor } \\
\text { CCR5 of CD4+ T-lymphocyte and blocks the binding to viral receptor } \\
\text { gp120) (9) }\end{array}$ \\
\hline MIV-150 & $\begin{array}{l}\text { Non-nucleoside inhibitor of HIV-1 reverse transcriptase (It is an allosteric } \\
\text { inhibitor that indirectly interferes with the catalytic mechanism of the } \\
\text { enzyme) (10) }\end{array}$ \\
\hline MK-2048 & $\begin{array}{l}\text { HIV-1 integrase strand transfer inhibitor (It block integration of viral cDNA } \\
\text { into the host cell genome) (11) }\end{array}$ \\
\hline Tenofovir & $\begin{array}{l}\text { Nucleotide reverse transcriptase inhibitor (It disrupts the synthesis of DNA } \\
\text { chain, used to integrate into cell genetic material) (12) }\end{array}$ \\
\hline Tenofovir disoproxil & $\begin{array}{l}\text { Nucleotide reverse transcriptase inhibitor (prodrug of tenofovir) (13) } \\
\text { fumarate }\end{array}$ \\
\hline TMC120 (dapivirine) & $\begin{array}{l}\text { Non-nucleoside inhibitor of HIV-1 reverse transcriptase (It is an allosteric } \\
\text { inhibitor that indirectly interferes with the catalytic mechanism of the } \\
\text { enzyme) (14) }\end{array}$ \\
\hline UC781 & $\begin{array}{l}\text { Non-nucleoside inhibitor of HIV-1 reverse transcriptase (It is an allosteric } \\
\text { inhibitor that indirectly interferes with the catalytic mechanism of the } \\
\text { enzyme) (15) }\end{array}$ \\
\hline $\begin{array}{l}\text { CCR5 antagonist (It binds to the chemokine receptor CCR5 of CD4 } \\
\text { T-lymphocyte and blocks the binding to viral receptor gp120 (16) }\end{array}$ \\
\hline
\end{tabular}

CCR5 - C-C chemokine receptor type 5, CD4 - transmembrane glycoprotein receptor for HIV-1, cDNA - complementary DNA, gp - glycoprotein

cific and specific can be considered as obsolete. It has been demonstrated in clinical testing that certain efficacy against HIV transmission is exhibited only by microbicides based on antivirals (Table I). However, for completeness we also provide information about clinical trials of the first-generation substances (Table II).

\section{UNSUCCESSFUL MICROBICIDE CANDIDATES FOR VAGINAL USE}

Microbicide clinical trials started with studies of non-specific and partially specific candidates. The first tested API was nonoxynol-9 from the surfactant family (Advantage 24, Columbia Research Laboratories, Rockville Center, New York, USA). Clinical trials were conducted from 1992-2002 with negative results. This surfactant, commonly used 
J. Vysloužil et al.: Clinical testing of antiretroviral drugs as future prevention against vaginal and rectal transmission of HIV infection - a review of currently available results, Acta Pharm. 69 (2019) 297-319.

Table II. List of non-specific and partially specific microbicide candidates

\begin{tabular}{|c|c|c|}
\hline Group & Microbicide & Effect \\
\hline Surfactants & $\begin{array}{l}\text { Nonoxynol-9, C31G, sodium } \\
\text { lauryl sulfate }\end{array}$ & $\begin{array}{l}\text { Disruption of the outer lipid membrane of } \\
\text { viral particle, contraceptive effect, effect } \\
\text { against several vaginal pathogens (17) }\end{array}$ \\
\hline $\begin{array}{l}\text { Substances keeping } \\
\text { physiological pH } \\
(3.8-4.2)\end{array}$ & $\begin{array}{l}\text { Polyacrylic acid, Carbopol }{ }^{\circledR} \\
974 \mathrm{P}\end{array}$ & $\begin{array}{l}\text { Buffering effect maintaining vaginal } \mathrm{pH} \\
\text { around physiological value and prevents } \\
\text { alkalization by semen ( } \mathrm{pH} 7.1-8.0 \text { ), viral } \\
\text { protein denaturation (18) }\end{array}$ \\
\hline \multirow{4}{*}{ Polyanionts } & $\begin{array}{l}\text { Carrageenans (linear } \\
\text { copolymers of D-galactose and } \\
\text { 3,6-anhydro-D-galactose; } \\
\text { sulfonated and unsulfonated } \\
\text { forms) }\end{array}$ & $\begin{array}{l}\text { Electrostatic interaction between the } \\
\text { negatively charged carrageenan surface } \\
\text { and the positively charged surface of HIV } \\
\text { - entry or fusion inhibitors with target } \\
\text { immune cells }(19,20)\end{array}$ \\
\hline & Polynaphthalene sulfonate & $\begin{array}{l}\text { Binding to HIV-1 gp120 and interference } \\
\text { with virus attachment to and/or fusion } \\
\text { with CD4 } 4^{+} \text {T-lymphocytes (also interaction } \\
\text { with CD4 and CXCR4 receptors) (21) }\end{array}$ \\
\hline & Cellulose sulfate & $\begin{array}{l}\text { Binding the gp } 120 \text { of HIV- } 1 \text { envelope, } \\
\text { inhibition of both CXCR } 4 \text { and CCR } 5 \text {, } \\
\text { inhibition of viral particle input or fusion } \\
\text { with target immune cells }(20,22)\end{array}$ \\
\hline & $\begin{array}{l}\text { Dendrimer SPL7013 (highly } \\
\text { branched, well-defined, } \\
\text { three-dimensional structures } \\
\text { with different surface groups) }\end{array}$ & $\begin{array}{l}\text { Blocking HIV-1 envelope mediated } \\
\text { cell-to-cell fusion, inhibition of viral entry } \\
\text { with similar potency against CXCR4 and } \\
\text { CCR5 (23) }\end{array}$ \\
\hline
\end{tabular}

$\mathrm{CD}_{4}^{+}$- transmembrane glycoprotein receptor for an HIV-1, CXCR4 chemokine receptor type 4, gp - glycoprotein

also as a spermicide (24), was applied as a gel (25), sponge (26) or film (27). However, it did not exert effective protection against HIV infection and, moreover, it caused damage of the vaginal mucous membranes and/or vaginitis. It was therefore excluded as a potential microbicide (28). Another surfactant, Savvy ${ }^{\circledR}$ (C31G; N,N-dimethyldodecanamine oxide 2-(dodecyldimethylazaniumyl)acetate) in gel form (C31G, Cellegy Pharmaceuticals Inc., Huntingdon Valley, Pennsylvania, USA), was shown to be a safe but yet ineffective form against HIV transmission (29). Phase III clinical testing took place in Nigeria and Ghana in 2004-2006.

The failure of surfactants was followed by clinical trials with polymeric substances of low toxicity such as poly-anions and substances keeping the acidic vaginal $\mathrm{pH}$ at a normal level. Even in this group, however, no significant success was recorded. Phase III clinical testing of an anionic cellulose sulfate (Ushercell ${ }^{\mathrm{TM}}$, Polydex Pharmaceuticals, Bahamas, tested as a $6 \%$ gel) conducted in India and Uganda was prematurely stopped because of the increased incidence of HIV infection compared to the placebo group. Anionic carrageenan (Carraguard $^{\circledR}$, FMC, USA), though non-irritable (5), showed no efficacy in the clinical study conducted in South Africa in 2004-2007 $(30,31)$. Similarly, no satisfactory results were 
J. Vysloužil et al.: Clinical testing of antiretroviral drugs as future prevention against vaginal and rectal transmission of HIV infection - a review of currently available results, Acta Pharm. 69 (2019) 297-319.

obtained for polynaphthalene sulfonate (PRO $2000^{\circledR}$, Endo Pharmaceuticals, Inc., USA) (32, 33). With high expectations, the dendrimer SPL7013 (Vivagel ${ }^{\text {, incorporated in carbomer }}$ gel; Starpharma Holdings Limited, Australia) was tested (23). In phase I clinical testing (2004), it was well tolerated by women (34). A clinical study (2008-2009) revealed $70 \%$ anti-HIV efficacy of vaginal fluid after the gel application (35). Unfortunately, though no other clinical study of Vivagel ${ }^{\circledR}$ as a microbicide has been performed yet, its therapeutic effect on vaginal inflammation was recently demonstrated (36). Buffer gel (a gel-based mucoadhesive preparation) (ReProtect LLC, USA) was tested for its ability to keep the vaginal $\mathrm{pH}$ acidic to support the vaginal mucosa natural defense (37). In a clinical trial, where it was tested together with PRO $2000^{\circledR}$, its efficacy was not demonstrated (38).

\section{ANTIVIRALS IN HIGHER PHASES OF CLINICAL TESTING}

Today, antiretroviral (ARV) APIs are at the forefront of interest. The most prominent ones are certainly tenofovir (TFV) and dapivirine (DPV). Basic information about completed clinical trials on antivirals during the period 2005-2018 is summarized in Tables III, IV and V.

\section{Clinical testing of tenofovir vaginal preparations}

In 2007-2009, a clinical trial called CAPRISA 004 (Centre for the AIDS Programme of Research in South Africa), phase IIb clinical testing of the $1 \%$ TFV hydrophilic gel took place as a double-blind, randomized, placebo-controlled clinical trial. The main aim of this clinical study was to investigate the safety and also the efficacy of this vaginal gel to prevent HIV infection among 889 participants from the South Africa region. Women used the gel before and after sexual intercourse. The gel was very well tolerated, both by sexually active and abstinent women (39). The results of the study confirmed an overall $39 \%$ efficacy, even with the inclusion of women who had rarely forgotten the application of gel during the study. Under strict adherence to the regime, the inclusion of women who applied the gel correctly was efficacious up to a promising $54 \%$ (40). The study also found that HIV transmission depended on TFV concentration in the cervico-vaginal fluid (CVF). At a concentration above $1000 \mathrm{ng} \mathrm{mL}^{-1}$, protection was demonstrated in $76 \%$ of volunteers (41).

Subsequently, in phase III, the clinical trial VOICE (Vaginal and oral interventions to control the epidemic) included more than five thousand women and was conducted in 2009-2012. Daily use of a $1 \%$ TFV gel was compared with oral tablets with TFV $\left(\right.$ Viread $^{\circledR}$; Gilead Sciences, Inc., USA) and the oral combination of TFV and emtricitabine (Truvada ${ }^{\circledR}$; Gilead Sciences, Inc., USA) (42). In comparison with CAPRISA 004, this brought shocking results on the efficacy of the $1 \%$ TFV gel. The preparation was proved to be completely ineffective without any positive result against HIV transmission. While the study participants reported $90 \%$ adherence confidence in keeping the study protocol, their adherence determined on the basis of plasma concentration was only $22 \%$.

In other trials, phase III clinical testing FACTS 001 (Follow-on African consortium for tenofovir studies) verifying the efficacy of the $1 \%$ TFV gel was run from 2011 to 2014 in South Africa. Among 2059 women, 123 cases of HIV infection were detected; 61 cases were found in the group using $1 \%$ TFV gel (applied before and after intercourse) and 62 in the placebo group. It is clear from this result that no significant effect of the $1 \%$ TFV gel was 


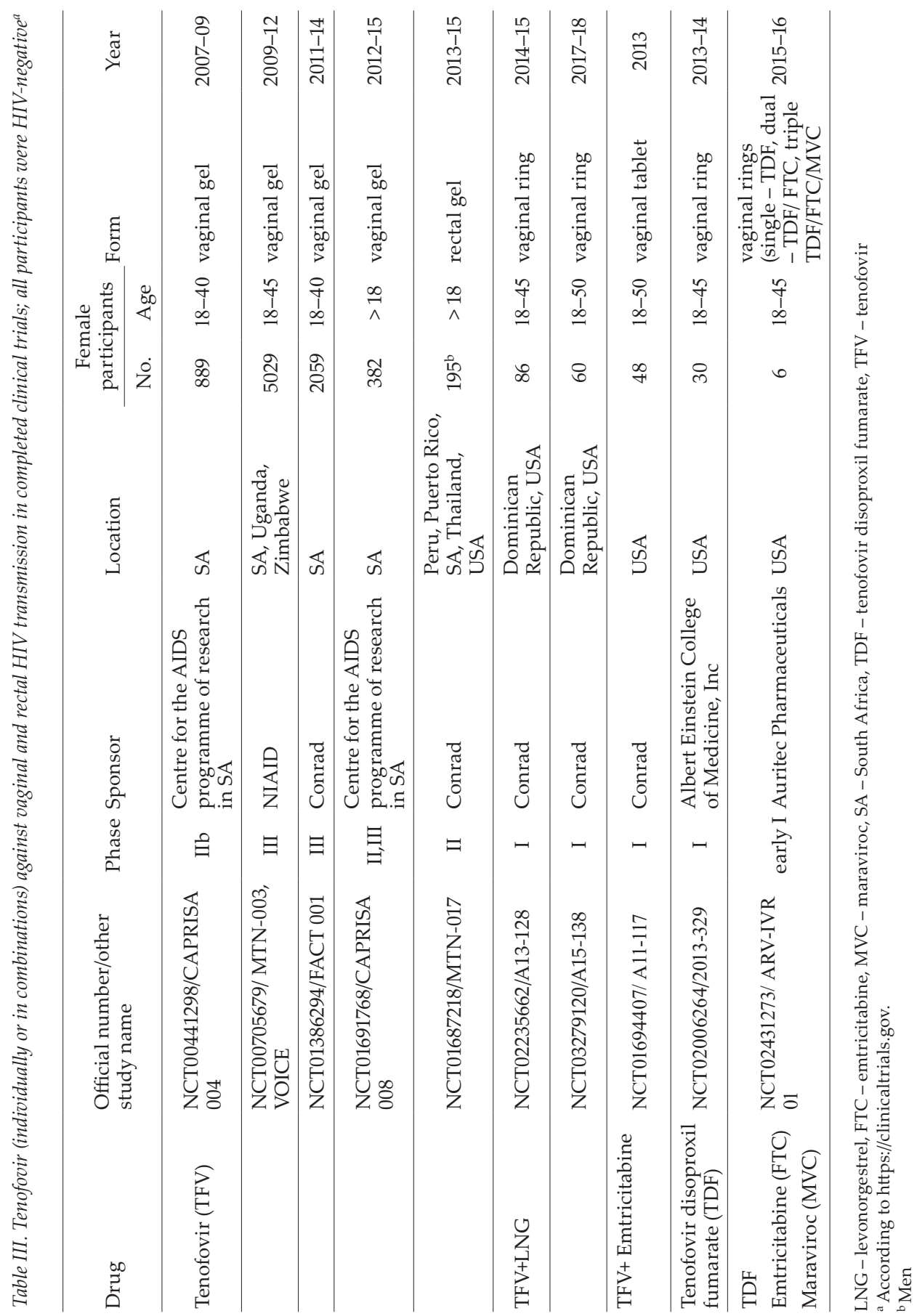




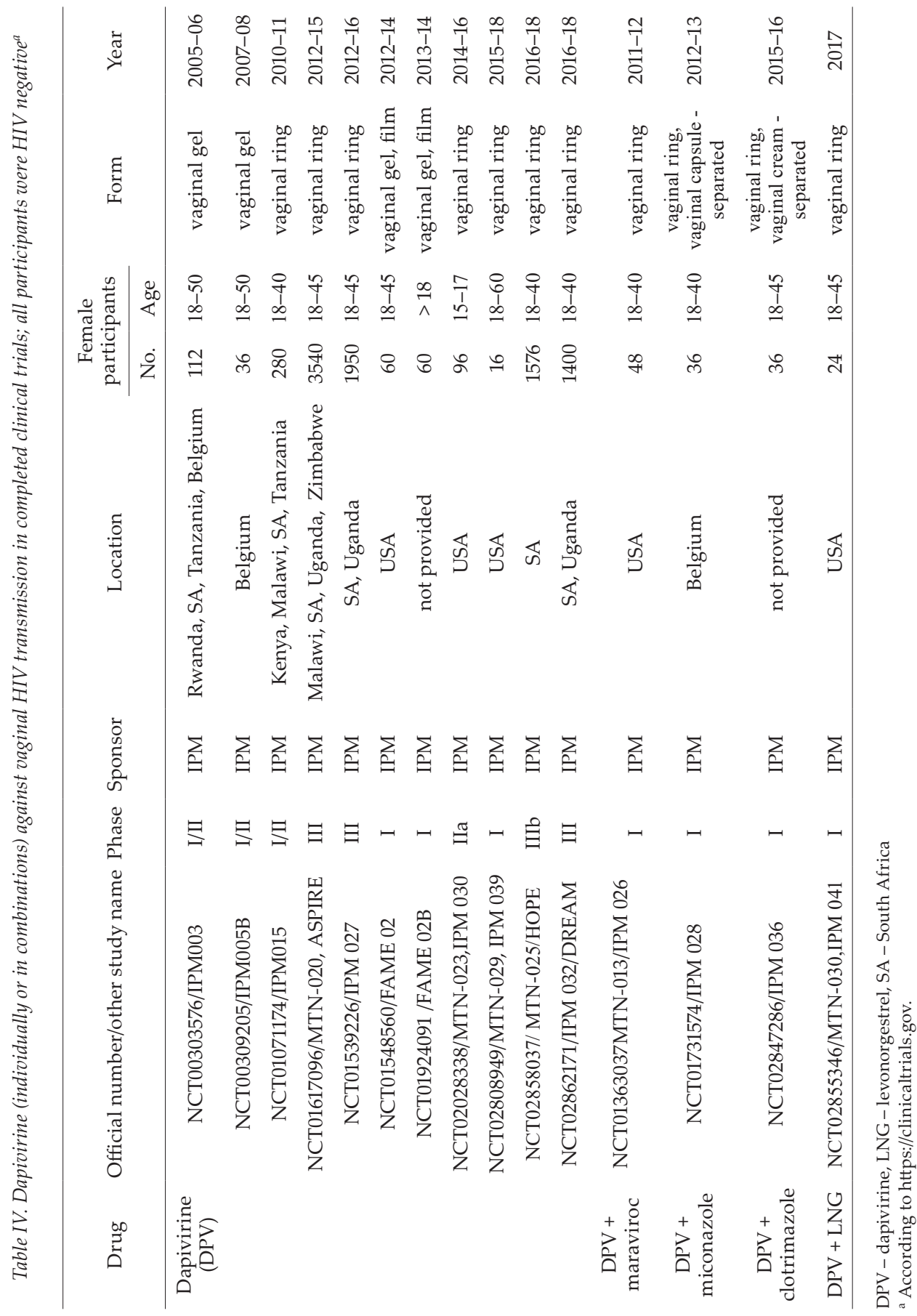




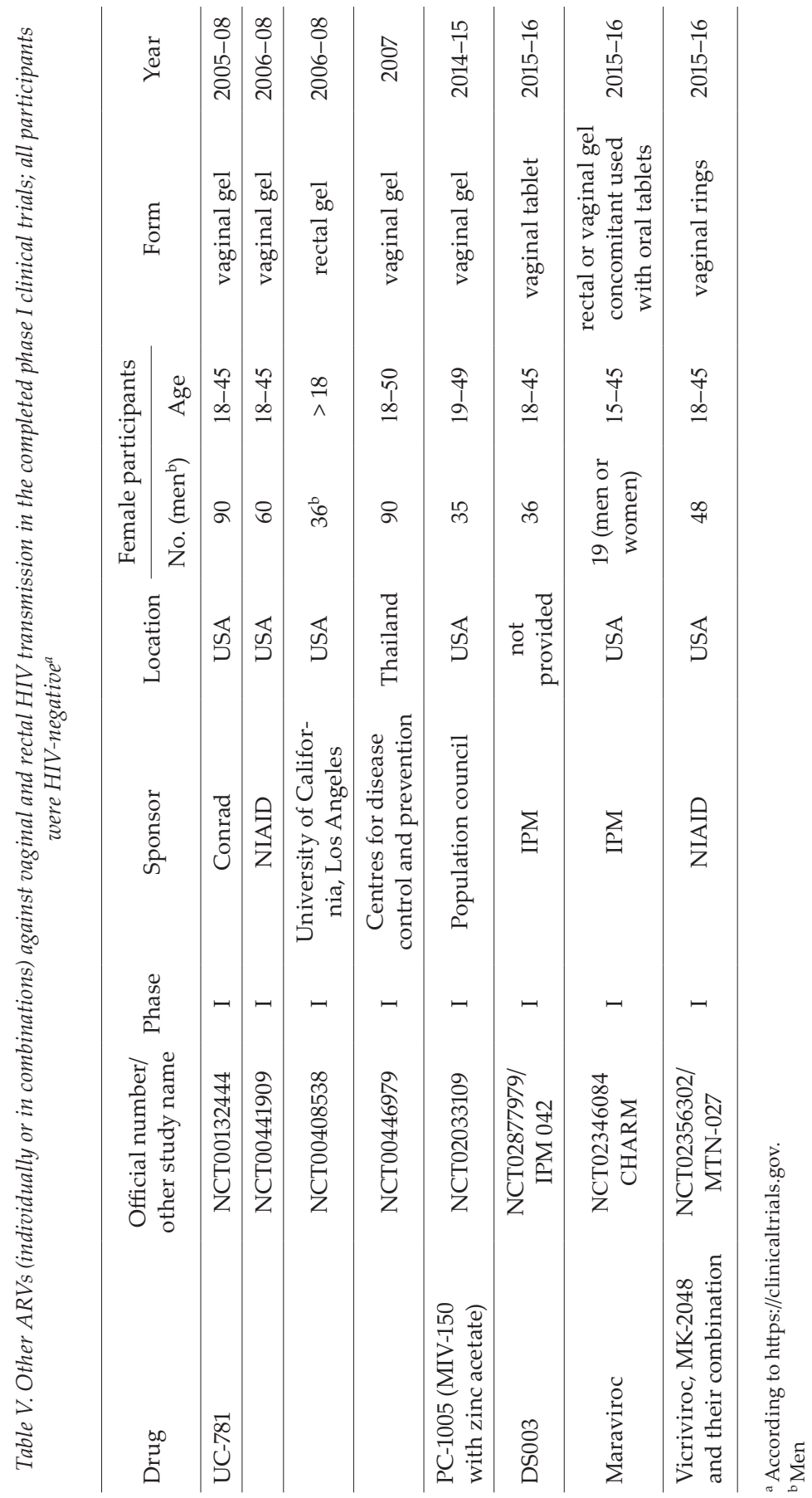


confirmed $(43,44)$. According to a detailed analysis of the results, a lack of discipline in women using this gel, especially young, single individuals, living with their parents, was probably responsible for the lack of effectiveness. Low compliance of the participants in the study was probably caused by the application form (gel) and the complicated administration regimen. It was revealed that gel application before and after a sexual intercourse was too demanding, especially for young women. The recently completed follow-up post-trial access study with the $1 \%$ TFV gel CAPRISA 008 (45) was focused on ensuring the adherence of participants with a coitus-related dosing regimen (exhibited through the mean number of returned used applicators per participant per month). The main approach was to integrate TFV gel (CONRAD, Arlington, Virginia, USA) provision into family planning services. Women participating in the relatively successful clinical trial CAPRISA 004 were invited for CAPRISA 008. The process of negotiating gel use was determined in part by the quality of the relationship such as its duration, living situation, culturally-defined steps, etc. (46).

However, according to the latest research, the reason for the TFV microbicide gel failure could also be seen in the composition of the vaginal microbiom of CAPRISA 004 participants (47). The results revealed that TFV reduced the HIV incidence by $61 \%$ in Lactobacillus-dominant women but only $18 \%$ in women with non-Lactobacillus bacteria. The detectible mucosal TFV concentration was lower in non-Lactobacillus women, yet negatively correlated with Gardnerella vaginalis and other anaerobic bacteria, which consequently depleted TFV in the female body more rapidly (48).

\section{Clinical testing of dapivirine vaginal preparations}

Clinical trials with DPV as an anti-HIV vaginal microbicide agent started in 2005. Two prospective, randomized, double-blind, placebo-controlled phase I/II clinical studies (IPM003) were conducted at five research centers in Africa and Belgium in 2005-2006. A group of 112 women were tested for safety, tolerability and systemic absorption of DPV from the vaginal gel $(0.02 \%)$ after its administration twice a day for 42 days; a group of 28 participants used placebo in the same regimen. A total of five serious adverse events occurred in these two studies, and none was assessed as related to the studied gel. The maximum observed mean concentration was $474 \mathrm{pg} \mathrm{mL}^{-1}$ on day 28 . Two weeks after the final application of the gel, mean concentrations decreased to $5 \mathrm{pg} \mathrm{mL}^{-1}$ or less. Based on the results, daily use was recognized as a safe and well tolerated method with low systemic absorption in healthy women (49).

Later in 2007-2008, the pharmacokinetics (PK) and safety study IPM005B (doubleblind, randomized, placebo-controlled) of two DPV vaginal gels was conducted in Belgium on 36 healthy women to assess plasma, vaginal fluid and vaginal tissue levels of DPV and PK of DPV when applying either gel 4750 (0.05\%, $2.5 \mathrm{~g})$ or $4789(0.05 \% 2.5 \mathrm{~g})$ (International Partnership for Microbicides, Bethlehem, Pennsylvania, USA) intravaginally for 11 days. This was done to assess the safety of these gels in comparison with the intravaginal hydroxyethyl cellulose (HEC) placebo gel. In conclusion, both gels were safe and well tolerated with low systemic absorption. The DPV concentration in vaginal fluids was more than 3 logs higher than plasma levels, which resulted in a significant reduction in viral load with oral DPV. Even though the DPV gel was successful in clinical testing, further investigation of its efficacy did not continue (50). 
J. Vysloužil et al.: Clinical testing of antiretroviral drugs as future prevention against vaginal and rectal transmission of HIV infection - a review of currently available results, Acta Pharm. 69 (2019) 297-319.

On the other hand, the dosage form with long-term drug release, the vaginal ring (VR), appeared in the following years (51). The VR can be defined as a self-administered, flexible, torus-shaped, matrix or reservoir drug delivery device based on indifferent biocompatible polymers, such as silicones, polyethylene-vinyl acetate polymer, or polyurethanes intended for prolonged release of several weeks or months (52).

IPM 015, a safety and acceptability I/II phase study of DPV vaginal ring ( $25 \mathrm{mg})$ (International Partnership for Microbicides, Silver Spring, Maryland, USA) was run in 20102011. The enrolled 280 women came from different places in Africa. Compared to the placebo VR, the DPV vaginal ring was generally perceived as safe and well-tolerated for up to 12 weeks of continuous use. Adverse events (pelvic abnormalities, vaginal discharge, intermenstrual bleeding) generally occurred with similar frequency for both DPV and placebo ring users. The majority of participants $(60 \%)$ in both ring groups reported that their male partners did not feel the ring. A further $22 \%$ reported that their partners felt the ring during the intercourse, but that it was not a problem. Only a small number (1-3 $\%)$ reported that her male partner felt the ring and that it might be, or definitely was, a problem for her to continue using it. Self-reported adherence to daily use of DPV VR was very high and the vaginal ring was acceptable to the majority of participants, who also reported that they would be willing to use it in the future if it was proven effective (53).

The DPV vaginal ring (QPharma, Malmö, Sweden, under contract with the International Partnership for Microbicides) is currently being evaluated in phase III clinical testing. A double-blind, randomized, placebo controlled clinical study ASPIRE (a study to prevent infection with a ring for extended use) was conducted in 2012-2015 with 2629 women involved from different parts of Africa. Overall, the results of this trial confirmed $27 \%$ efficacy to prevent HIV infection. Significant dependence of efficacy on the age of participants was clearly demonstrated. For women under 25, only a $10 \%$ result rate was shown while the efficacy for women older than 25 years was up to $61 \%$ (54). A similar study (IPM 027) was conducted among 1959 healthy sexually active women aged from 18 to 45 originating from seven communities in South Africa and Uganda. The incidence of HIV-1 infection had a $31 \%$ lower result rate in the DPV group than in the placebo one. There was no significant difference in DPV VR efficacy in dependence on age. Among participants with a HIV-1 infection, non-nucleoside reverse-transcriptase inhibitor resistance mutations were detected in $18.2 \%$ of the participants in the DPV group and $16.1 \%$ in the placebo group (55).

Given the potential for interactions with co-administered vaginal products, PK assessments were made during the co-use of the DPV vaginal ring and a commonly used antifungal API miconazole nitrate (MN) $(1200 \mathrm{mg})$ in the form of vaginal capsules. The clinical trial IPM 028 was conducted in Belgium among 36 healthy women. Participants used the DPV VR so called Ring-004 (QPharma, Malmö, Sweden) for 28 days, alone or together with a single dose of MN. Concomitant use of the two products was safe and well tolerated. One product-related adverse event occurred (vulvovaginal candidiasis - in the arm of ring alone). A single vaginal dose of $\mathrm{MN}$ at the time of DPV vaginal ring insertion increased the systemic exposure of DPV by approximately $20 \%$, but decreased DPV CVF levels up to 14 days post ring insertion. CVF levels remained sufficient for HIV-1 inhibition in cervical tissue. Local and systemic miconazole exposure was increased after co-administration with DPV Ring-004 (1.4 to 6-fold higher). Concomitant use of Ring-004 with a single vaginal dose of MN altered the local and systemic levels of both drugs, but these changes were considered unlikely to affect adversely the efficacy of either drug (56). Later, 
J. Vysloužil et al.: Clinical testing of antiretroviral drugs as future prevention against vaginal and rectal transmission of HIV infection - a review of currently available results, Acta Pharm. 69 (2019) 297-319.

a similar clinical study (IPM 036) investigating the drug-drug interaction between Ring004 and a cream containing $1 \%$ clotrimazole was already completed, but no scientific data are currently available (57).

The fate of the DPV ring continued in a clinical study known as MTN-023/IPM 030. It was designed to provide the kind of information about safety and tolerability of DPV VR that regulatory authorities would need to expand the approval of the ring to include its use also for girls under the age of 18 (58). The study was a multi-center, two-arm, randomized, double-blind, placebo-controlled phase IIa clinical trial. Objectives of the trial included the evaluation of acceptability and adherence to a VR when inserted once every 4 weeks for a 24-week period with evaluation of local and systemic DPV exposure. The VR was found to be safe and acceptable by American adolescent girls. There were no differences in safety outcomes between the treatment arms (3:1 to a DPV or placebo ring). In the DPV group, drug levels indicated adherence in $87 \%$ of plasma samples and $95 \%$ of rings. Participants noted no discomfort due to the ring at $87 \%$ of visits and "liking" the ring at $93 \%$ of visits (59). This VR subsequently entered the phase I clinical testing (MTN-029/IPM 039) for breastfeeding women. The study was not blinded, focusing on the PK of the drug and the transfer of DPV into breast milk. Women included in the study had stopped breastfeeding their babies but could still produce breast milk, which was also analyzed. They were asked to leave the VR in place for 14 days. All participants had detectable DPV levels in plasma and milk with median peaks of $676 \mathrm{pg} \mathrm{mL}^{-1}$ and $327 \mathrm{pg} \mathrm{mL}^{-1}$, resp. Researchers estimated that an infant's daily exposure to the drug would be very low (68.0 $\mathrm{ng} \mathrm{kg}^{-1}$ per day) and without any substantial health risks for breastfed infants (60).

Similarly, like in the case of TFV gel, adherence measurement of the vaginal ring use within the clinical trial setting remains a challenge for the HIV prevention field. Direct post-use measurement of the rest drug assay could be used as a suitable approach towards understanding and assessing adherence (61).

The newest phase III/IIIb clinical studies are MTN-025 (HOPE) (62) and IPM 032 (DREAM) (63) focusing on the safety of and adherence to the DPV (25 mg) Ring-004 inserted at monthly intervals. These open-label trials included participants from the South Africa region. Although the trial is not yet completed, preliminary results presented at the Conference on Retroviruses and Opportunistic Infections in Boston (2018) indicated a similar safety profile of DVR to that observed in phase III. Both studies found high adherence ( $90 \%$ of returned rings had residual levels of DPV consistent with at least some use). HIV incidence in both studies was much lower than expected - $1.9 \%$ per year for HOPE and $1.8 \%$ per year for DREAM; these are much lower than the placebo incidence in ASPIRE (>4\% per year). The results were remarkably similar and showed that the HIV incidence observed in the open-label extension studies was about $54 \%$ lower than expected. More analyses of the studies will be coming in the next couple of years (64).

\section{CURRENT CHALLENGES}

\section{The most suitable dosage form for microbicides}

For women, the future use of microbicide preparations could be certainly seen in the form of a vaginal ring. When compared to gel, the vaginal ring ensures satisfactory compliance with the dosing regimen (65). Final clarification of this issue could be found in 
J. Vysloužil et al.: Clinical testing of antiretroviral drugs as future prevention against vaginal and rectal transmission of HIV infection - a review of currently available results, Acta Pharm. 69 (2019) 297-319.

the recently completed clinical trial QUATRO conducted in South Africa and Zimbabwe and sponsored by CONRAD. The purpose of the QUATRO study was to assess the users' experience, acceptability, preferences and the effect on sexual behaviour of four different vaginal delivery forms: the rapidly disintegrating vaginal insert, vaginal ring, film and gel. The results are expected in the near future $(66,67)$. Although gels and vaginal rings are currently considered as the most suitable application forms, the research focuses also on other dosage forms. The proof is the phase I clinical testing FAME 02 and FAME 02B of a novel DPV vaginal film (composed of polyvinyl alcohol). The FAME 02 study was focused on its safety, acceptability, PK and pharmacodynamics (PD). Participants were randomized to a daily DPV (0.05\%) (Microbicide Trials Network, Silver Spring, Maryland, USA) or placebo gel (CONRAD, Arlington, Virginia, USA), or DPV (1.25 mg) or placebo film for seven days. Women rated the film more comfortable with less leakage but found it more difficult to insert than gel. Both film and gel delivered DPV at concentrations sufficient to block HIV ex vivo (68). In FAME 02B, participants were randomized to receive either DPV vaginal gel or DPV vaginal film of the same drug dose $(1.25 \mathrm{mg})$. Occurrence of mild to moderate adverse events was similar among the products. The DPV film and gel performed similarly in terms of tolerability, pharmacokinetics, and reduction of cervical tissue infectivity after ex vivo HIV challenge 5 hours post dose (69).

It can also be noted that some recent clinical trials investigated microbicide drugs formulated into vaginal tablets, as it will be mentioned later. On the other hand, gels and enemas are the most suitable dosage forms for rectal administration so far (70).

\section{Antiretroviral APIs firstly used for vaginal administration}

At present, different antiretroviral drugs, which have not yet been used for this purpose, appear in the first phases of clinical testing (Table V). Some information about these active agents can be found in the literature and official internet sources.

Although the antiretroviral effect of thiocarboxanilide UC-781 has been tested since 2005, it still remains only in phase I clinical testing. The first clinical study NCT00132444 was focused on the safety and acceptability of $0.1 \%$ UC-781 and $0.25 \%$ UC-781 Carbopol $^{\circledR}$ gel (CONRAD, Arlington, Virginia, USA) administered vaginally twice a day for 14 days in two intermenstrual weeks (71). Even many years after completion, the results of this clinical study are not available. Similarly, the clinical trial NCT00441909 was conducted to reveal local and systemic safety for a one-time dosage of UC-781 $0.1 \%$ gel for vaginal use for different durations of exposure $(2,4,8 \mathrm{~h})$ in HIV uninfected women (72). Only 2 women in the drug-loaded gel group had detectable systemic UC781 levels, however below the limits of quantification. The most frequently reported adverse events were genitourinary with a similar distribution in the placebo and UC-781 gel arms. Vaginal secretion was collected to test antiviral activity against HIV and assess the amount of microbicide remaining in the vagina. The initial CVF drug concentration was significantly higher than the known $I C_{50}$ for HIV-1. Active drug levels were detected in CVF and vaginal swab specimens on days 1-2 at concentrations supporting daily dosing (73). Located in Thailand, the second parallel clinical study NCT00446979 controlled by placebo (HEC) with the twice a day application regimen for 14 days was targeted at safety and acceptability of the UC-781 gel only for women and their male partners (74). Partial results of this clinical study were published by Haaland et al. (75). Only a group of 25 Thai women was included in testing of whether UC781 retained anti-infective activity follow- 
J. Vysloužil et al.: Clinical testing of antiretroviral drugs as future prevention against vaginal and rectal transmission of HIV infection - a review of currently available results, Acta Pharm. 69 (2019) 297-319.

ing exposure to the female genital tract. Ex vivo analysis of the UC781 levels and antiHIV-1 activity in the soluble supernatant fraction (CVF-s) and pelletable fraction (CVF-p) of CVF were determined. As UC781 is highly hydrophobic, there were significantly higher levels of UC781 in the CVF-p samples than in the CVF-s samples for the UC781 gel arms. Especially in the $0.25 \%$ UC781 gel arms, infection with $\geq 4 \log 1050 \%$ tissue culture infective dose of HIV-1 was efficiently blocked. This study also confirmed a $93 \%$ self-reported adherence to gel use. The numbers and types of adverse events were similar in the study arms. Despite satisfactory results in phase I clinical testing, the UC 781 gel did not progress to other phases.

In the phase I clinical testing NCT02006264, the polyurethane vaginal ring with a content of tenofovir disoproxil fumarate (TDF) was used continuously for 14 consecutive days in 30 women to investigate the safety and PK in a randomized single-blinded placebo VR controlled regimen. Drug concentrations were measured in CVF, cervical tissue, plasma and dried blood spots. During the study, there were eight product-related mild adverse events. CVF collected from the cervix one week and two weeks after the TDF VR insertion provided significant protection against ex vivo HIV challenge. The TDF VR was recognized as safe, well tolerated, and resulted in mucosal TFV concentrations that exceeded those associated with HIV protection (76).

For the first time administered vaginally, PC-1005 (combination of MIV-150 and zinc acetate in carrageenan gel) was tested in the phase I clinical trial NCT02033109 evaluating its safety, PK and acceptability (77). In the end, only 20 participants were included into the published data. Used vaginally for 14 days, PC-1005 (Center for Biomedical Research, New York, USA) was well tolerated by the participants. One third of participants reported they liked the gel; two thirds recommended reducing its volume. Low systemic levels of MIV150 were observed and plasma zinc levels were unchanged. The post-dose CVF samples showed anti-HIV and anti-human papilloma virus activity (78).

The new, promising antiretroviral drug DS003 was tested in the form of vaginal tablets in a double-blinded phase I clinical trial IPM 042 to determine their safety and tolerability. It was the first time that DS003 was being studied in humans. The trial was supposed to be completed in the second half of 2016 (79). The results are still unavailable.

\section{Combination of more antiretroviral drugs for vaginal application}

The new approach in this field is a combination of more antiviral drugs in one preparation, which is considered to be a more effective approach with lower likelihood of resistance. Phase I clinical testing (MTN-013/IPM 026) of VRs containing $25 \mathrm{mg}$ of DPV and $100 \mathrm{mg}$ of maraviroc (MVC) and their combination (DPV/MVC ring), resp., has been completed $(80,83)$. The randomized double-blinded study was designed to determine the safety, PK and PD. It can be concluded that all the tested rings were safe and well tolerated without adverse effects for a period of 28 days. DPV/MVC rings had higher peak concentrations $\left(C_{\max }\right)$ and overall drug exposure $(A U C)$ in CVF compared to the rings with individual drugs. The early peak and significant gradual fall in concentration of MVC indicated an inefficient drug delivery profile that resulted in early drug exposure excess (toxicity risk) and lower concentrations later (lack of efficacy risk). In the DPV preparation without MVC, a concentration-dependent inhibition of HIV-1 in cervical tissue was demonstrated. DPV concentrations in CVF were 100,000 times higher than plasma concentrations. MVC 
J. Vysloužil et al.: Clinical testing of antiretroviral drugs as future prevention against vaginal and rectal transmission of HIV infection - a review of currently available results, Acta Pharm. 69 (2019) 297-319.

concentrations were detectable only in CVF; however, the plasma levels were mostly beyond detectable limits, therefore further study of MVC release from VR is needed.

A combination of antiretroviral drugs TFV and emtricitabine (FTC) in the form of vaginal tablets was very successful in a preclinical study (81). A phase I clinical safety/PK trial of these tablet formulations was currently completed (NC01694407). In this first-inwomen study, the individual dose of TFV and FTC was $40 \mathrm{mg}$ each. Unfortunately, the results are still expected (82).

Another clinical trial, MTN-027, evaluated the safety and PK of vicriviroc (VCV), integrase inhibitor MK-2048 and their combination $(84,85)$. In all cases, drugs were incorporated in the vaginal ring. Drug concentrations were quantified in the plasma, vaginal fluid, cervical tissue, and rectal fluid. Cervical tissue was utilized for the ex vivo HIV inhibition analysis. VCV and/or MK-2048 containing VRs were safe and acceptable. Most women (77 $\%$ ) fully adhered to 28 days of continuous VR use and found the VR acceptable. Both VCV and MK-2048 were quantifiable in all the matrixes tested with peak drug concentrations similar for both single and combination drug VRs. Tissue-associated VCV and/or MK-2048 did not correlate with the inhibition of HIV infection. Therefore, a new investigation of drug dosing in VRs is needed.

In the early phase I clinical study NCT02431273 (open-label safety, acceptability and pharmacokinetic study), the single pod-vaginal ring with TDF, dual vaginal ring containing drugs TDF/FTC and triple vaginal ring containing TDF/FTC/MVC for HIV prophylaxis were studied for 7 days $(86,87)$. Reported acceptability was high for all the three products. There were no serious adverse events during the study. No epithelial disruption/ thinning was seen by colposcopy, and no systematic vaginal microbiome changes were observed. Tissue concentrations of the drugs used exceeded the theoretical target concentrations for vaginal HIV prevention. In this study, a rectal drug exposure was also investigated. It can be concluded from the results that concentrations of FTC and MVC in the obtained rectal fluids exceeded the levels associated with in vitro efficacy in HIV inhibition. MVC appeared to reduce the distribution of TDV and FTC into the rectal lumen. Nevertheless, this strategy seems to be useful for dual-compartment protection.

\section{Combination of antiretroviral drug with other APIs for vaginal application}

The future expected output is likely to be a combination of microbicides with other drugs such as agents protecting from other sexually transmitted pathogens (18) or contraceptive drugs known as MultiPurpose Technologies developed by CONRAD (88). Preclinical studies with a multifunctional VR containing TFV and levonorgestrel (LNG) indicated that the VR is capable of sustained release of both drugs for 90 days (89). The TFV/ LNG VR is the first multipurpose prevention technology designed to reduce HIV, herpes infections and unplanned pregnancies. The phase I clinical study named CONRAD 128 assessed the safety, acceptability, and APIs' PK/PD (90). Participants were using VR for approximately 15 days. TFV/LNG VRs (TFV - $10 \mathrm{mg}$ per day; LNG - $20 \mu \mathrm{g}$ per day) were safe with no significant colposcopic, mucosal, immune or microbiota changes and were acceptable to women. Estimated in vivo, TFV and LNG release rates were within expected ranges. CVF of women completely inhibited HIV infection in vitro, the majority (95\%) were anovulatory or had abnormal cervical mucus sperm penetration. TFV/LNG rings are ready for expanded 90 day clinical testing (NCT03279120, completed 12/2018). 
Similarly, the three-month VR to protect women against HIV and unintended pregnancy was tested in a MTN-030/IPM 041 study at two different locations in the USA (91). It is the first in-human study of VR containing a combination of DPV (200 mg) and LNG (320 $\mathrm{mg}$ ). This clinical trial is completed but the results have not been published yet.

\section{Male and female rectal microbicide gel}

The future of microbicides can also be seen in the development of a male and female rectal microbicide gel. The closest to clinical practice is a rectal preparation based on reduced glycerol content and $1 \%$ TFV (CONRAD, Arlington, Virginia, USA). It is currently in the recently completed phase II clinical trial MTN-017. Its safety, drug absorption and tolerance after rectal administration were monitored. The study was attended by 195 men from the USA, Africa, Peru and Taiwan in 2013-2015 (92, 93). Adherence and product use likelihood were higher for the intermittent gel regimen (before and after anal intercourse) than for the daily gel use also due to the occurrence of diarrhea as an adverse event. The adherence of participants with intermittent gel regimens was $93 \%$, whereas adherence with the daily rectal regimen was only $83 \%$.

The phase I clinical trial NCT00408538 investigated the UC-781 microbicide gel ( $0.1 \%$ and $0.25 \%$; CONRAD, Arlington, Virginia, USA), which was applied rectally in participants of both sexes as a randomized, blinded, placebo-controlled safety and acceptability study (94). After using the UC-781 gel rectally for seven consecutive days, the participants' feedback suggested that the UC-781 gel formulation was highly acceptable and comparable to a placebo gel. Rectal exposure to both concentrations of UC781 was safe with no significant adverse events, no detected plasma drug levels and no significant mucosal changes. Ex vivo biopsy infections demonstrated marked suppression of HIV infectibility (more evident for $0.25 \%$ concentration).

The antiretroviral drug MVC was examined in the phase I clinical trial NCT02346084 where a $1 \%$ gel was tested in adult participants of both sexes (95). This trial was a randomized, open label, crossover safety and PK study of oral MVC tablets and $1 \%$ MVC gel administered rectally and vaginally in HIV-1 seronegative adults. The purpose of the study was to evaluate the safety, acceptability and the PK/PD profile of MVC gel following rectal and vaginal administration in comparison with oral MVC exposure. However, the results are still unavailable.

\section{CONCLUSIONS}

In the above mentioned clinical trials, a total of almost 20,000 participants were recruited. Male participants were represented by only less than $1.5 \%$. Obviously, investigation of microbicides is currently focused on solving the problem of HIV transmission via vaginal route in the female population. Hydrophilic gels and VRs are most frequently selected as application forms. A recent clinical trial using films and vaginal tablets can be found. From the tested substances, only the most prominent tenofovir and dapivirine progressed into phase III clinical testing, other ARVs were investigated meanwhile in phase I. ARVs and generally exhibited safety and good tolerability comparable with the control group using placebo. The HIV inhibition activity in vaginal fluid ex vivo was recognized as satisfactory in many cases. The real efficacy of microbicide preparations was tested on $1 \% \mathrm{TFV}$ and 
J. Vysloužil et al.: Clinical testing of antiretroviral drugs as future prevention against vaginal and rectal transmission of HIV infection - a review of currently available results, Acta Pharm. 69 (2019) 297-319.

DPV VR with $25 \mathrm{mg}$ of API. The efficacy of TFV gel in CAPRISA 004 exhibited a maximum value of $39 \%$ against HIV transmission. On the other hand, the same gel completely failed in VOICE, FACT001. Thus, its efficacy is considered as fluctuating and strictly dependent on the user's compliance with the application regimen (efficacy $54 \%$ under strict patient adherence). Nevertheless, the $1 \%$ TFV gel was integrated into family planning services in the post-trial access study CAPRISA 008. The other successful candidate, DPV incorporated into the ring, exhibited $27 \%$ efficacy with an age-related dependency ( $61 \%$ over 25 years) in ASPIRE. The same VR was also relatively successful in IPM 027 with $31 \%$ efficacy without age dependency. In the newest clinical trials HOPE and DREAM, preliminary results have shown as high as $54 \%$ efficacy. At present, there is not enough evidence to conclusively recommend topical microbicides for HIV prevention. Further studies are needed to confirm the clearly beneficial effects of microbicide preparations with a focus on participant adherence. Only this can open the way to rapid regulatory approval and their maximal spread in the sexually active population.

Acknowledgements. - This work was supported by IGA VFU Brno Czech Republic (306/2016/FaF).

Acronyms, abbreviations, symbols. - AIDS - acquired immunodeficiency syndrome, APIs - active pharmaceutical ingredients, ARV - antiretroviral, ASPIRE - study to prevent infection with a ring for extended use, CAPRISA 004 - Centre for the AIDS Programme of Research in South Africa, DPV - dapivirine, FACTS 001 - Follow-on African Consortium for Tenofovir Studies, HEC - intravaginal hydroxyethyl cellulose, HIV - human immunodeficiency virus, HPV - human papilloma virus, HSV2 - Herpes simplex virus $2, I C_{50}$ - half maximal inhibitory concentration, IPM - International partnership for microbicides, LNG - levonorgestrel, MN - miconazole nitrate, NIAID - National Institute of Allergy and Infectious Diseases, PD - pharmacodynamics, PK - pharmacokinetics, TDF - tenofovir disoproxil fumarate, TFV - tenofovir, VOICE - vaginal and oral interventions to control the epidemic, VR - vaginal ring, WHO - World Health Organization.

\section{REFERENCES}

1. M. Peeters, M. D'Arc and E. Delaporte, The origin and diversity of human retroviruses, AIDS Rev. 16 (2014) 23-34.

2. World Health Organization, Progress Report 2016: Prevent HIV, Test and Treat All: WHO Support for Country Impact, WHO, 2016; http://www.who.int/iris/handle/10665/251713; last access date January 18, 2019.

3. J. M. Excler and N. L. Michael, Lessons from HIV-1 vaccine efficacy trials, Curr. Opin. HIV AIDS 11 (2016) 607-613; https://doi.org/10.1097/COH.0000000000000312

4. Z. A. Stein, Vaginal microbicides and prevention of HIV infection, Lancet 343 (1994) 362-363; https://doi.org/10.1016/S0140-6736(94)91205-X

5. J. Balzarini and L. Van Damme, Microbicide drug candidates to prevent HIV infection, Lancet $\mathbf{3 6 9}$ (2007) 787-797; https://doi.org/10.1016/S0140-6736(07)60202-5

6. L. M. Ferguson and L. C. Rohan, The importance of the vaginal delivery route for antiretrovirals in HIV prevention, Ther. Deliv. 2 (2011) 1535-1550; https://doi.org/10.4155/tde.11.126

7. Z. Si, N. Madani, J. M. Cox, J. J. Chruma, J. C. Klein, A. Schön, N. Phan, L. Wang, A. C. Biorn, S. Cocklin, I. Chaiken, E. Freire, A. B. Smith III and J. G. Sodroski, Small-molecule inhibitors of HIV1 entry block receptor-induced conformational changes in the viral envelope glycoproteins, Proc. Natl. Acad. Sci. USA 101 (2004) 5036-5041; https://doi.org/10.1073/pnas.0307953101

8. L. D. Saravolatz and M. S. Saag, Emtricitabine, a new antiretroviral agent with activity against HIV and hepatitis B virus, Clin. Infect. Dis. 42 (2006) 126-131; https://doi.org/https://doi. org $/ 10.1086 / 498348$ 
J. Vysloužil et al.: Clinical testing of antiretroviral drugs as future prevention against vaginal and rectal transmission of HIV infection - a review of currently available results, Acta Pharm. 69 (2019) 297-319.

9. N. Ray, Maraviroc in the treatment of HIV infection, Drug Des. Devel. Ther. 2 (2008) 151-161; https:// doi.org/10.2147/DDDT.S3474

10. J. Kenney, M. Aravantinou, R. Singer, M. Hsu, A. Rodriguez, L. Kizima, C. J. Abraham, R. Menon, S. Seidor, A. Chudolij, A. Gettie, J. Blanchard, J. D. Lifson, M. Piatak Jr., J. A. Fernández-Romero, T. M. Zydowsky and M. Robbiani, Antiretroviral/zinc combination gel provides 24 hours of complete protection against vaginal SHIV infection in macaques, PLoS ONE 6 (2011) e15835; https:// doi.org/10.1371/journal.pone.0015835

11. T. Bar-Magen, R. D. Sloan, D. A. Donahue, B. D. Kuhl, A. Zabeida, H. Xu, M. Oliveira, D. J. Hazuda and M. A. Wainberg, Identification of novel mutations responsible for resistance to MK-2048, a second-generation HIV-1 integrase inhibitor, J. Virol. 84 (2010) 9210-9216; https://doi.org/10.1128/ JVI.01164-10

12. A. S. Ray, M. W. Fordyce and M. J. Hitchcock, Tenofovir alafenamide: A novel prodrug of tenofovir for the treatment of human immunodeficiency virus, Antiviral Res. 125 (2016) 63-70; https://doi. org/10.1016/j.antiviral.2015.11.009

13. B. P. Kearney, J. F. Flaherty and J. Shah, Tenofovir disoproxil fumarate clinical pharmacology and pharmacokinetics, Clin. Pharmacokinet. 43 (2004) 595-616; https://doi.org/10.2165/00003088200443090-00003

14. S. Di Fabio, J. Van Roey, G. Giannini, G. van den Mooter, M. Spada, A. Binelli, M. F. Pirillo, E. Germinario, F. Belardelli, M. P. de Bethune and S. Vella, Inhibition of vaginal transmission of HIV-1 in hu-SCID mice by the non-nucleoside reverse transcriptase inhibitor TMC120 in a gel formulation, AIDS 17 (2003) 1597-1604; https://doi.org/10.1097/01.aids.0000072663.21517.63

15. J. Balzarini, H. Pelemans, S. Aquaro, C. F. Perno, M. Witvrouw, D. Schols, E. De Clercq and A. Karlsson, Highly favorable antiviral activity and resistance profile of the novel thiocarboxanilide pentenyloxy ether derivatives UC-781 and UC-82 as inhibitors of human immunodeficiency virus type 1 replication, Mol. Pharmacol. 50 (1996) 394-401.

16. T. J. Wilkin, Z. Su, A. Krambrink, J. Long, W. Greaves, R. Gross, M. D. Hughes, C. Flexner, P. R. Skolnik, E. Coakley, C. Godfrey, M. Hirsch, D. R. Kuritzkes and R. M. Gulick, Three-year safety and efficacy of vicriviroc, a CCR5 antagonist, in HIV-1-infected, treatment-experienced patients, J. Acquir. Immune Defic. Syndr. 5 (2010) 470-476; http://doi.org/10.1097/QAI.0b013e3181e2cba0

17. N. J. Alexander, E. Baker, M. Kaptein, U. Karc, L. Mille and E. Zampaglione, Why consider vaginal drug administration?, Fertil. Steril. 82 (2004) 1-12; https://doi.org/10.1016/j.fertnstert.2004.01.025

18. D. R. Friend and P. F. Kiser, Assessment of topical microbicides to prevent HIV-1 transmission: Concepts, testing, lessons learned, Antiviral Res. 99 (2013) 391-400; https://doi.org/10.1016/j.antiviral.2013.06.021

19. D. J. Schaeffer and V. S. Krylov, Anti-HIV activity of extracts and compounds from algae and cyanobacteria, Ecotoxicol. Environ. Saf. 45 (2000) 208-227; https://doi.org/10.1006/eesa.1999.1862

20. B. Cutler and J. Justman, Vaginal microbicides and the prevention of HIV transmission, Lancet Infect. Dis. 8 (2008) 685-697; https://doi.org/10.1016/S1473-3099(08)70254-8

21. D. Huskens, K. Vermeire, A. T. Profy and D. Schols, The candidate sulfonated microbicide, PRO 2000, has potential multiple mechanisms of action against HIV-1, Antiviral Res. 84 (2009) 38-47; https://doi.org/10.1016/j.antiviral.2009.07.013

22. L. Van Damme, R. Govinden, F. M. Mirembe, F. Guédou, S. Solomon, M. L. Becker, B. S. Pradeep, A. K. Krishnan, M. Alary, B. Pande, G. Ramjee, J. Deese, T. Crucitti, D. Taylor and CS study group, Lack of effectiveness of cellulose sulfate gel for the prevention of vaginal HIV transmission, $N$. Engl. J. Med. 359 (2008) 463-472; https://doi.org/10.1056/NEJMoa0707957

23. D. Tyssen, S. A. Henderson, A. Johnson, J. Sterjovski, K. Moore, J. La, M. Zanin, S. Sonza, P. Karellas, M. P. Giannis, G. Krippner, S. Wesselingh, T. McCarthy, P. R. Gorry, P. A. Ramsland, R. Cone, J. R. Paull, G. R. Lewis and G. Tachedjian, Structure activity relationship of dendrimer microbicides with dual action antiviral activity, PLOS ONE 5 (2010) e12309; https://doi.org/10.1371/journal. pone.0012309 
J. Vysloužil et al.: Clinical testing of antiretroviral drugs as future prevention against vaginal and rectal transmission of HIV infection - a review of currently available results, Acta Pharm. 69 (2019) 297-319.

24. D. Serfaty, Contraception during perimenopause: The spermicides option, J. Gynecol. Obstet. Hum. Reprod. 46 (2017) 211-218; https://doi.org/10.1016/j.jogoh.2016.10.007

25. L. Van Damme, G. Ramjee, M. Alary, B. Vuylsteke, V. Chandeying, H. Rees, P. Sirivongrangson, L. Mukenge-Tshibaka, V. Ettiègne-Traoré, C. Uaheowitchai, S. S. Karim, B. Mâsse, J. Perriëns, M. Laga and COL-1492 study group, Effectiveness of COL-1492, a nonoxynol-9 vaginal gel, on HIV-1 transmission in female sex workers: a randomised controlled trial, Lancet 360 (2002) 971-977; https://doi.org/10.1016/S0140-6736(02)11079-8

26. J. Kreiss, E. Ngugi, K. Holmes, J. Ndinya-Achola, P. Waiyaki, P. L. Roberts, I. Ruminjo, R. Sajabi, J. Kimata, T. R. Fleming, A. Anzala, D. Holton and F. Plummer, Efficacy of nonoxynol 9 contraceptive sponge use in preventing heterosexual acquisition of HIV in Nairobi prostitutes, JAMA 268 (1992) 477-482; https://doi.org/10.1001/jama.1992.03490040053025

27. R. E. Roddy, L. Zekeng, K. A. Ryan, U. Tamoufé, S. S. Weir and E. L. Wong, A controlled trial of nonoxynol 9 film to reduce male-to-female transmission of sexually transmitted diseases, N. Engl. J. Med. 339 (1998) 504-510; https://doi.org/10.1056/NEJM199808203390803

28. D. Wilkinson, M. Tholandi, G. Ramjee and G. W. Rutherford, Nonoxynol-9 spermicide for prevention of vaginally acquired HIV and other sexually transmitted infections: systematic review and meta-analysis of randomised controlled trials including more than 5000 women, Lancet Infect. Dis. 2 (2002) 613-617; https://doi.org/10.1016/S1473-3099(02)00396-1

29. P. J. Feldblum, A. Adeiga, R. Bakare, S. Wevill, A. Lendvay, F. Obadaki, M. O. Olayemi, L. Wang, K. Nanda and W. Rountree, SAVVY vaginal gel (C31G) for prevention of HIV infection: a randomized controlled trial in Nigeria, PLOS ONE 3 (2008) e1474; https://doi.org/10.1371/journal. pone.0001474

30. S. Skoler-Karpoff, G. Ramjee, K. Ahmed, L. Altini, M. G. Plagianos, B. Friedland, S. Govender, A. De Kock, N. Cassim, T. Palanee, G. Dozier, R. Maguire and P. Lahteenmaki, Efficacy of Carraguard for prevention of HIV infection in women in South Africa: a randomised, double-blind, placebocontrolled trial, Lancet 372 (2008) 1977-1987; https://doi.org/10.1016/S0140-6736(08)61842-5

31. The Carraguard Phase II South Africa study team, Expanded safety and acceptability of the candidate vaginal microbicide Carraguard ${ }^{\circledR}$ in South Africa, Contraception 82 (2010) 563-571; https:// doi.org/10.1016/j.contraception.2010.04.019

32. S. McCormack, G. Ramjee, A. Kamali, H. Rees, A. M. Crook, M. Gafos, U. Jentsch, R. Pool, M. Chisembele, S. Kapiga, R. Mutemwa, A. Vallely, T. Palanee, Y. Sookrajh, C. J. Lacey, J. Darbyshire, H. Grosskurth, A. Profy, A. Nunn, R. Hayes and J. Weber, PRO2000 vaginal gel for prevention of HIV-1 infection (Microbicides development programme 301): a phase 3, randomised, doubleblind, parallel-group trial, Lancet 376 (2010) 1329-1337; https://doi.org/10.1016/S0140-6736(10)610860

33. V. Pirrone, B. Wigdahl and F. C. Krebs, The rise and fall of polyanionic inhibitors of the human immunodeficiency virus type 1, Antiviral. Res. 90 (2011) 168-182; https://doi.org/10.1016/j.antiviral.2011.03.176

34. T. D. McCarthy, P. Karellas, S. A. Henderson, M. Giannis, D. F. O'Keefe, G. Heery, J. R. Paull, B. R. Matthews and G. Holan, Dendrimers as drugs: discovery and preclinical and clinical development of dendrimer-based microbicides for HIV and STI prevention, Mol. Pharm. 2 (2005) 312-318; https://doi.org/10.1021/mp050023q

35. C. F. Price, D. Tyssen, S. Sonza, A. Davie, S. Evans, G. R. Lewis, S. Xia, T. Spelman, P. Hodsman, T. R. Moench, A. Humberstone, J. R. Paull and G. Tachedjian, SPL7013 Gel (VivaGel ${ }^{\circledR}$ ) retains potent HIV-1 and HSV-2 inhibitory activity following vaginal administration in humans, PLoS ONE 6 (2011) e24095; https://doi.org/10.1371/journal.pone.0024095

36. M. Hiorth, S.Nilsen and I. Tho, Bioadhesive mini-tablets for vaginal drug delivery, Pharmaceutics 6 (2014) 494-511; https://doi.org/10.3390/pharmaceutics6030494 
J. Vysloužil et al.: Clinical testing of antiretroviral drugs as future prevention against vaginal and rectal transmission of HIV infection - a review of currently available results, Acta Pharm. 69 (2019) 297-319.

37. C. Kempf, P. Jentsch, F. B. Barre-Sinoussi, B. Poirier, J. J. Morgenthaler, A. Morell and D. Germann, Inactivation of human immunodeficiency virus (HIV) by low $\mathrm{pH}$ and pepsin, J. Acquir. Immune Defic. Syndr. 4 (1991) 828-830.

38. S. S. A. Karim, B. A. Richardson, G. Ramjee, I. F. Hoffman, Z. M. Chirenje, T. Taha, M. Kapina, L. Maslankowski, A. Coletti, A. Profy, T. R. Moench, E. Piwowar-Manning, B. Mâsse, S. L. Hillier, L. Soto-Torres and HIV prevention trials network (HPTN) 035 study team, Safety and effectiveness of BufferGel and 0.5\% PRO2000 gel for the prevention of HIV infection in women, AIDS 25 (2011) 957-966; https://doi.org/10.1097/QAD.0b013e32834541d9

39. K. H. Mayer, L. A. Maslankowski, F. Gai, W. M. El-Sadr, J. Justman, A. Kwiecien, B. Mâsse, S. H. Eshleman, C. Hendrix, K. Morrow, J. F. Rooney, L. Soto-Torres and HPTN 050 protocol team, Safety and tolerability of tenofovir vaginal gel in abstinent and sexually active HIV-infected and uninfected women, AIDS 20 (2006) 543-451; https://doi.org/10.1097/01.aids.0000210608.70762.c3

40. Q. A. Karim, S. S. A. Karim, J. A. Frohlich, A. C. Grobler, C. Baxter, L. E. Mansoor, A. B. Kharsany, S. Sibeko, K. P. Mlisana, Z. Omar, T. N. Gengiah, S. Maarschalk, N. Arulappan, M. Mlotshwa, L. Morris, D. Taylor and CAPRISA 004 trial group, Effectiveness and safety of tenofovir gel, an antiretroviral microbicide, for the prevention of HIV infection in women, Science 329 (2010) 11681174; https://doi.org/10.1126/science.1193748

41. A. D. Kashuba, T. N. Gengiah, L. Werner, K. H. Yang, N. R. White, Q. A. Karim and S. S. A. Karim, Genital tenofovir concentrations correlate with protection against HIV infection in the CAPRISA 004 trial: Importance of adherence for microbicide effectiveness, J. Acquir. Immune Defic. Syndr. 69 (2015) 264-269; https://doi.org/10.1097/QAI.0000000000000607

42. J. M. Marrazzo, G. Ramjee, B. A. Richardson, K. Gomez, N. Mgodi, G. Nair, T. Palanee, C. Nakabiito, A. van der Straten, L. Noguchi, C. W. Hendrix, J. Y. Dai, S. Ganesh, B. Mkhize, M. Taljaard, U. M. Parikh, J. Piper, B. Mâsse, C. Grossman, J. Rooney, J. L. Schwartz, H. Watts, M. A. Marzinke, S. L. Hillier, I. M. McGowan, Z. M. Chirenje and VOICE study team, Tenofovir-based preexposure prophylaxis for HIV infection among African women, N. Engl. J. Med. 372 (2015) 509-518; https:// doi.org/10.1056/NEJMoa1402269

43. Q. A. Karim, C. Baxter and S. A. Karim, Microbicides and their potential as a catalyst for multipurpose sexual and reproductive health technologies, BJOG 12 (2014) 53-61; https://doi. org/10.1111/1471-0528.12843

44. H. Rees, S. A. Delany-Moretlwe, C. Lombard, D. Baron, R. Panchia, L. Myer, J. L. Schwartz, G. F. Doncel and G. Gray, FACTS 001 phase III trial of pericoital tenofovir 1\% gel for HIV prevention in women, in Conference on Retroviruses and Opportunistic Infections, February 23-26, 2015, Seattle, Washington, abstract no. 26LB; https://www.croiconference.org/sessions/facts-001-phase-iii-trialpericoital-tenofovir-1-gel-hiv-prevention-women; last access date January 18, 2019.

45. L. E. Mansoor, Q. A. Karim, K. T. Mngadi, S. Dlamini, C. Montague, N. Nkomonde, N. Mvandaba, C. Baxter, T. N. Gengiah, N. Samsunder, H. Dawood, A. Grobler, J. A. Frohlich and S. S. A. Karim, Assessing the implementation effectiveness and safety of $1 \%$ tenofovir gel provision through family planning services in KwaZulu-Natal, South Africa: study protocol for an open-label randomized controlled trial, Trials 15 (2014) Article ID 496 (9 pages); https://doi.org/10.1186/1745-621515-496

46. K. M. MacQueen, S. Dlamini, B. Perry, E. Okumu, S. Sortijas, C. Singh, D. Pillay, A. Majors, S. Jerome, S. Watson, S. A. Karim, Q. A. Karim and L. E. Mansoor, Social context of adherence in an open-label 1\% tenofovir gel trial: gender dynamics and disclosure in KwaZulu-Natal, South Africa, AIDS Behav. 20 (2016) 2682-2691; https://doi.org/10.1007/s10461-016-1339-4

47. J. Cohen, Infectious disease. Vaginal microbiome affects HIV risk, Science 353 (2016) 331; https:// doi.org/10.1126/science.353.6297.331

48. N. R. Klatt, R. Cheu, K. Birse, A. S. Zevin, M. Perner, L. Noël-Romas, A. Grobler, G. Westmacott, I. Y. Xie, J. Butler, L. Mansoor, L. R. McKinnon, J. S. Passmore, Q. A. Karim, S. S. A. Karim and A. D. 
J. Vysloužil et al.: Clinical testing of antiretroviral drugs as future prevention against vaginal and rectal transmission of HIV infection - a review of currently available results, Acta Pharm. 69 (2019) 297-319.

Burgener, Vaginal bacteria modify HIV tenofovir microbicide efficacy in African women, Science 356 (2017) 938-945; https://doi.org/10.1126/science.aai9383

49. A. M. Nel, P. Coplan, J. H. van de Wijgert, S. H. Kapiga, C. von Mollendorf, E. Geubbels, J. Vyankandondera, H. V. Rees, G. Masenga, I. Kiwelu, J. Moyes and S. C. Smythe, Safety, tolerability, and systemic absorption of dapivirine vaginal microbicide gel in healthy, HIV-negative women, AIDS 23 (2009) 1531-1538; https://doi.org/10.1097/QAD.0b013e32832c413d

50. A. M. Nel, S. C. Smythe, S. Habibi, P. E. Kaptur and J. W. Romano, Pharmacokinetics of 2 dapivirine vaginal microbicide gels and their safety vs. hydroxyethyl cellulose-based universal placebo gel, J. Acquir. Immune Defic. Syndr. 55 (2010) 161-169; https://doi.org/10.1097/QAI.0b013e3181e3293a

51. B. Devlin, J. Nuttall, S. Wilder, C. Woodsong and Z. Rosenberg, Development of dapivirine vaginal ring for HIV prevention, Antiviral Res. 100 (2013) S3-S8; https://doi.org/10.1016/j.antiviral.2013.09.025

52. R. K. Malcolm, P. J. Boyd, C. F. McCoy and D. J. Murphy, Microbicide vaginal rings: Technological challenges and clinical development, Adv Drug Deliv Rev. 103 (2016) 33-56; https://doi.org/10.1016/j. addr.2016.01.015

53. A. Nel, L. G. Bekker, E. Bukusi, E. Hellstrøm, P. Kotze, C. Louw, F. Martinson, G. Masenga, E. Montgomery, N. Ndaba, A. van der Straten, N. van Niekerk and C. Woodsong, Safety, acceptability and adherence of dapivirine vaginal ring in a microbicide clinical trial conducted in multiple countries in Sub-Saharan Africa, PLoS ONE 11 (2016) e0147743; https://doi.org/10.1371/journal. pone.0147743

54. J. M. Baeten, T. Palanee-Phillips, E. R. Brown, K. Schwartz, L. E. Soto-Torres, V. Govender, N. M. Mgodi, F. Matovu Kiweewa, G. Nair, F. Mhlanga, S. Siva, L. G. Bekker, N. Jeenarain, Z. Gaffoor, F. Martinson, B. Makanani, A. Pather, L. Naidoo, M. Husnik, B. A. Richardson, U. M. Parikh, J. W. Mellors, M. A. Marzinke, C. W. Hendrix, A. van der Straten, G. Ramjee, Z. M. Chirenje, C. Nakabiito, T. E. Taha, J. Jones, A. Mayo, R. Scheckter, J. Berthiaume, E. Livant, C. Jacobson, P. Ndase, R. White, K. Patterson, D. Germuga, B. Galaska, K. Bunge, D. Singh, D. W. Szydlo, E. T. Montgomery, B. S. Mensch, K. Torjesen, C. I. Grossman, N. Chakhtoura, A. Nel, Z. Rosenberg, I. McGowan, S. Hillier, and MTN-020-ASPIRE study team, Use of a vaginal ring containing dapivirine for HIV-1 prevention in women, N. Engl. J. Med. 375 (2016) 2121-2132; https://doi.org/10.1056/NEJMoa1506110

55. A. Nel, N. van Niekerk, S. Kapiga, L. G. Bekker, C. Gama, K. Gill, A. Kamali, P. Kotze, C. Louw, Z. Mabude, N. Miti, S. Kusemererwa, H. Tempelman, H. Carstens, B. Devlin, M. Isaacs, M. Malherbe, W. Mans, J. Nuttall, M. Russell, S. Ntshele, M. Smit, L. Solai, P. Spence, J. Steytler, K. Windle, M. Borremans, S. Resseler, J. Van Roey, W. Parys, T. Vangeneugden, B. Van Baelen, Z. Rosenberg and Ring study team, Safety and efficacy of a dapivirine vaginal ring for HIV prevention in women, N. Engl. J. Med. 375 (2016) 2133-2143; https://doi.org/10.1056/NEJMoa1602046

56. A. Nel, W. Haazen, M. Russell, J. Nuttall, N. Van Niekerk and N. Treijtel, Drug-drug interactions between the dapivirine vaginal ring (Ring-004) and miconazole nitrate vaginal capsule (GynoDaktarin $\left.{ }^{\circledR}\right)$, AIDS Res. Hum. Retroviruses 30 (2014) A144. https://doi.org/10.1089/aid.2014.5291.abstract

57. To assess the drug-drug interaction potential between dapivirine vaginal ring-004, containing 25 $\mathrm{mg}$ of dapivirine, and clotrimazole $10 \mathrm{mg} / \mathrm{g}$ (1\%); https://clinicaltrials.gov/ct2/show/record/ NCT02847286; last access date January 18, 2019.

58. V. Jespers, C. Noestlinger and K. K. Ariën, Designing microbicides against HIV: innovative rings for young women urgently needed, Future Virol. 12 (2017) 45-48; https://doi.org/10.2217/fvl-20160135

59. K. Bunge, L. Levy, D. Szydlo, J. Zhang, A. Gaur, D. Reirden, K. Mayer, D. Futterman, C. Hoesley, S. Hillier, M. Marzinke, C. Dezzutti, C. Wilson, L. Soto-Torres, B. Kapogiannis, A. Nel, K. Squires, and MTN-023/IPM 030 protocol team, Safety and acceptability trial of the dapivirine vaginal ring 
J. Vysloužil et al.: Clinical testing of antiretroviral drugs as future prevention against vaginal and rectal transmission of HIV infection - a review of currently available results, Acta Pharm. 69 (2019) 297-319.

in U.S. adolescents, The 9th IAS Conference on HIV Science (IAS 2017), July 23-26, 2017, Paris (France); http://programme.ias2017.org/Abstract/Abstract/5540; last access date January 27, 2019.

60. L. Noguchi, R. Beigi, J. Biggio, M. Marzinke, C. Kelly, K. Bunge, R. Scheckter, J. Piper, S. Hillier, A. $\mathrm{Nel}$ and C. Hendrix, Breast milk dapivirine pharmacokinetics, estimated infant exposure, and safety during dapivirine intravaginal ring use among lactating women, Am. J. Obstet. Gynecol. 217 (2017) 717-717; https://doi.org/10.1016/j.ajog.2017.08.089

61. P. Spence, A. Nel, N. van Niekerk, T. Derrick, S. Wilder and B. Devlin, Post-use assay of vaginal rings (VRs) as a potential measure of clinical trial adherence, J. Pharm. Biomed. Anal. 125 (2016) 94-100; https://doi.org/10.1016/j.jpba.2016.03.023

62. Trial to assess the continued safety of and adherence to a vaginal ring containing dapivirine in women; https://clinicaltrials.gov/ct2/show/record/NCT02858037?term=MTN-025\&rank=1\&view= record; last access date January 27, 2019.

63. To assess continued safety of and adherence to the dapivirine ( $25 \mathrm{mg}$ ) vaginal ring-004 in healthy, HIV-negative Women; https://clinicaltrials.gov/ct2/show/NCT02862171?term=IPM+032\&rank=1; last access date January 27, 2019.

64. J. Baeten and C. Celum, HIV Prevention at CROI 2018 and PrEP updates on PrEP - disparities; current \& future; delivery/use/barriers; women, transmission clusters, Conference on Retroviruses and Opportunistic Infections, Boston (MA), USA, March 4-7, 2018; http://www.natap. org/2018/CROI/croi_188.htm; last access date January 27, 2019.

65. R. K. Malcolm, K. L. Edwards, P. Kiser, J. Romano and T. J. Smith, Advances in microbicide vaginal rings, Antiviral Res. 88 (2010) S30-S39; https://doi.org/10.1016/j.antiviral.2010.09.003

66. The quatro study: Acceptability study of (placebo) vaginal delivery forms for preventing HIV and unintended pregnancy; https://clinicaltrials.gov/ct2/show/NCT02602366; last access date January $18,2019$.

67. T. A. Jacot, M. R. Clark, O. E. Adedipe, S. Godbout, A. G. Peele, S Ju, J. L. Schwartz, A. R. Thurman and G. F. Doncel, Development and clinical assessment of new objective adherence markers for four microbicide delivery systems used in HIV prevention studies, Clin. Transl. Med. 7 (2018) 3737; https://doi.org/10.1186/s40169-018-0213-6

68. K. E. Bunge, C. S. Dezzutti, L. C. Rohan, C. W. Hendrix, M. A. Marzinke, N. Richardson-Harman, B. J. Moncla, B. Devlin, L. A. Meyn, H. M. Spiegel and S. L. Hillier, A phase 1 trial to assess the safety, acceptability, pharmacokinetics, and pharmacodynamics of a novel dapivirine vaginal film, J. Acquir. Immune Defic. Syndr. 71 (2016) 498-505; https://doi.org/10.1097/QAI.0000000000000897

69. J. A. Robinson, M. A. Marzinke, R. P. Bakshi, E. J. Fuchs, C. L. Radebaugh, W. Aung, H. M. Spiegel, J. S. Coleman, L. C. Rohan and C. W. Hendrix, Comparison of dapivirine vaginal gel and film formulation pharmacokinetics and pharmacodynamics (FAME 02B), AIDS Res. Hum. Retroviruses 33 (2017) 339-346; https://doi.org/10.1089/AID.2016.0040

70. H. Agashe, M. Hu and L. Rohan, Formulation and delivery of microbicides, Curr. HIV Res. 10 (2012) 88-96; https://doi.org/10.2174/157016212799304599

71. Study of UC-781 vaginal microbicide; https:/clinicaltrials.gov/ct2/show/record/NCT00132444?ter $\mathrm{m}=\mathrm{NCT} 00132444 \& \mathrm{rank}=1$; last access date January 18, 2019.

72. Phase I study of safety and persistence of UC-781 vaginal microbicide; https://clinicaltrials.gov/ ct2/show/NCT00441909?term=NCT00441909\&rank=1; last access date January 21, 2019.

73. K. Bunge, I. Macio, L. Meyn, L. Noguchi, M. A. Parniak, J. L. Schwartz, B. Moncla and S. Hillier, The safety, persistence, and acceptability of an antiretroviral microbicide candidate UC781, J. Acquir. Immune Defic. Syndr. 60 (2012) 337-343; https://doi.org/10.1097/QAI.0b013e3182575914

74. Safety study of UC-781 vaginal microbicide; https://clinicaltrials.gov/ct2/show/NCT00446979?ter $\mathrm{m}=\mathrm{NCT} 00446979 \&$ rank=1; last access date January 21, 2019. 
J. Vysloužil et al.: Clinical testing of antiretroviral drugs as future prevention against vaginal and rectal transmission of HIV infection - a review of currently available results, Acta Pharm. 69 (2019) 297-319.

75. R. E. Haaland, T. Evans-Strickfaden, A. Holder, C. P. Pau, J. M. McNicholl, C. Chaikummao, W. Chonwattana and C. E. Hart, UC781 microbicide gel retains anti-HIV activity in cervicovaginal lavage fluids collected following twice-daily vaginal application, Antimicrob. Agents Chemother. 56 (2012) 3592-3596; https://doi.org/10.1128/AAC.00452-12

76. M. J. Keller, P. M. Mesquita, M. A. Marzinke, R. Teller, L. Espinoza, J. M. Atrio, Y. Lo, B. Frank, S. Srinivasan, D. N. Fredricks, L. Rabe, P. L. Anderson, C. W. Hendrix, P. F. Kiser and B. C. Herold, A phase 1 randomized placebo-controlled safety and pharmacokinetic trial of a tenofovir disoproxil fumarate vaginal ring, AIDS30(2016)743-751; https://doi.org/10.1097/QAD.0000000000000979

77. O. Mizenina, M. Hsu, N. Jean-Pierre, M. Aravantinou, K. Levendosky, G. Paglini, T. M. Zydowsky, M. Robbiani and J. A. Fernández-Romero, MIV-150 and zinc acetate combination provides potent and broad activity against HIV-1, Drug Deliv. Transl. Res. 7 (2017) 859-866; https://doi.org/10.1007/ s13346-017-0421-4

78. B. A. Friedland, C. J. Hoesley, M. Plagianos, E. Hoskin, S. Zhang, N. Teleshova, M. Alami, L. Novak, K. R. Kleinbeck, L. L. Katzen, T. M. Zydowsky, J. A. Fernández-Romero and G. W. Creasy, First-in-human trial of MIV-150 and zinc acetate coformulated in a carrageenan gel: safety, pharmacokinetics, acceptability, adherence, and pharmacodynamics, J. Acquir. Immune Defic. Syndr. 73 (2016) 489-496; https://doi.org/10.1097/QAI.0000000000001136

79. Evaluate the safety and assess local and systemic PK of DS003 vaginal tablets administered to healthy HIV-negative women; https:/clinicaltrials.gov/ct2/show/NCT02877979?term=IPM+042\&r ank=1; last access date January 21, 2019

80. S. M. Fetherston, P. Boyd, C. F. McCoy, M. C. McBride, K. L. Edwards, S. Ampofo and R. K. Malcolm, A silicone elastomer vaginal ring for HIV prevention containing two microbicides with different mechanisms of action, Eur. J. Pharm. Sci. 48 (2013) 406-415; https://doi.org/10.1016/j. ejps.2012.12.002

81. M. R. Clark, M. M. Peet, S. Davis, G. F. Doncel and D. R. Friend, Evaluation of rapidly disintegrating vaginal tablets of tenofovir, emtricitabine and their combination for HIV-1 prevention, Pharmaceutics 6 (2014) 616-631; https://doi.org/10.3390/pharmaceutics6040616

82. Safety, pharmacokinetics, pharmacodynamics, and disintegration time of vaginal tablets containing tenofovir and/or emtricitabine; https://clinicaltrials.gov/ct2/show/study/NCT01694407?term=e mtricitabine+vaginal\&rank=2; last access date January 27, 2019.

83. B. A. Chen, L. Panther, M. A. Marzinke, C. W. Hendrix, C. J. Hoesley, A. van der Straten, M. J. Husnik, L. Soto-Torres, A. Nel, S. Johnson, N. Richardson-Harman, L. K. Rabe and C. S. Dezzutti, Phase 1 safety, pharmacokinetics, and pharmacodynamics of dapivirine and maraviroc vaginal rings: a double-blind randomized trial, J. Acquir. Immune Defic. Syndr. 70 (2015) 242-249; https://doi. org/10.1097/QAI.0000000000000702

84. Safety and pharmacokinetics of intravaginal rings containing vicriviroc (MK-4176) and/or MK2048; https://clinicaltrials.gov/ct2/show/NCT02356302?term=MTN-027\&rank=1; last access date January 21, 2019.

85. C. J. Hoesley, B. A. Chen, P. L. Anderson, C. S. Dezzutti, J. Strizki, C. Sprinkle, F. Heard, J. Bauermeister, W. Hall, C. Jacobson, J. Berthiaume, A. Mayo, H. Gundacker, N. Richardson-Harman and J. Piper, Microbicide Trials Network 027 Study Team, Phase 1 safety and pharmacokinetics study of MK-2048/vicriviroc (MK-4176)/MK-2048A intravaginal rings, Clin. Infect. Dis., Oct 2018 (in press); https://doi.org/10.1093/cid/ciy653

86. Safety and pharmacokinetic study of hiv prophylaxis using antiretroviral intravaginal rings in healthy women; https://clinicaltrials.gov/ct2/show/NCT02431273?term=NCT02431273\&rank=1; last access date January 27, 2019.

87. K. L. Vincent, J. A. Moss, M. A. Marzinke, C. W. Hendrix, P. A. Anton, R. B. Pyles, K. M. Guthrie, L. Dawson, T. J. Olive, I. Butkyavichene, S. A. Churchman, J. M. Cortez Jr, R. Fanter, M. Gunawardana, C. S. Miller, F. Yang, R. K. Rosen, S. E. Vargas and M. M. Baum, Safety and pharmacokinetics 
of single, dual, and triple antiretroviral drug formulations delivered by pod-intravaginal rings designed for HIV-1 prevention: A phase I trial, PLOS Med. 15 (2018) e1002655; https://doi. org/10.1371/journal.pmed.1002655

88. R. Sitruk-Ware, A. Nath and D. R. Mishell, Jr., Contraception technology: past, present and future. Contraception 87 (2013) 319-330; https://doi.org/10.1016/j.contraception.2012.08.002

89. J. T. Clark, M. R. Clark, N. B. Shelke, T. J. Johnson, E. M. Smith, A. K. Andreasen, J. S. Nebeker, J. Fabian, D. R. Friend and P. F. Kiser, Engineering a segmented dual-reservoir polyurethane intravaginal ring for simultaneous prevention of HIV transmission and unwanted pregnancy, PLoS ONE 9 (2014) e88509; https://doi.org/10.1371/journal.pone.0088509

90. A. R. Thurman, J. L. Schwartz, V. Brache, M. R. Clark, T. McCormick, N. Chandra, M. A. Marzinke, F. Z. Stanczyk, C. S. Dezzutti, S. L. Hillier, B. C. Herold, R. Fichorova, S. N. Asin, C. Rollenhagen, D. Weiner, P. Kiser and G. F. Doncel, Randomized, placebo controlled phase I trial of safety, pharmacokinetics, pharmacodynamics and acceptability of tenofovir and tenofovir plus levonorgestrel vaginal rings in women, PLOS ONE 13 e0199778; https://doi.org/10.1371/journal. pone. 0199778

91. PK and safety study of vaginal rings containing dapivirine and levonorgestrel (DAP/LNG); https://clinicaltrials.gov/ct2/show/NCT02855346?term=MTN-030\%2FIPM+041\&rank=1; last access date January 21, 2019.

92. R. D. Cranston, J. R. Lama, B. A. Richardson, A. Carballo-Diéguez, R. P. Kunjara Na Ayudhya, K. Liu, K. B. Patterson, C. S. Leu, B. Galaska, C. E. Jacobson, U. M. Parikh, M. A. Marzinke, C. W. Hendrix, S. Johnson, J. M. Piper, C. Grossman, K. S. Ho, J. Lucas, J. Pickett, L. G. Bekker, S. Chariyalertsak, A. Chitwarakorn, P. Gonzales, T. H. Holtz, A. Y. Liu, K. H. Mayer, C. Zorrilla, J. L. Schwartz, J. Rooney, I. McGowan and MTN-017 protocol team, A rectal phase 2 extended safety and acceptability study of tenofovir reduced-glycerin 1\% gel, Clin. Infect. Dis. 64 (2017) 614-620; https://doi.org/10.1093/cid/ciw832

93. A. Carballo-Diéguez, I. C. Balán, W. Brown, R. Giguere, C. Dolezal, C. Leu, M. A. Marzinke, C. W. Hendrix, J. M. Piper, B. A. Richardson, C.Grossman, S. Johnson, K. Gomez, S. Horn, R. P. K. Na Ayudhya, K. Patterson, C. Jacobson, L. Bekker, S. Chariyalertsak, A. Chitwarakorn, P. Gonzales, T. H. Holtz, A. Liu, K. H. Mayer, C. Zorrilla, J. Lama, I. McGowan and R. D. Cranston, High levels of adherence to a rectal microbicide gel and to oral pre-exposure prophylaxis (PrEP) achieved in MTN-017 among men who have sex with men (MSM) and transgender women, PLOS ONE 12 e0181607; https://doi.org/10.1371/ journal.pone.0181607

94. P. A. Anton, T. Saunders, J. Elliott, E. Khanukhova, R. Dennis, A. Adler, G. Cortina, K. Tanner, J. Boscardin, W. G. Cumberland, Y. Zhou, A. Ventuneac, A. Carballo-Diéguez, L. Rabe, T. McCormick, H. Gabelnick, C. Mauck and I. McGowan, First phase 1 double-blind, placebocontrolled, randomized rectal microbicide trial using UC781 gel with a novel index of ex vivo efficacy, PLoS ONE 6 (2011) e23243; https://doi.org/10.1371/journal.pone.0023243

95. Safety and pharmacokinetic study of oral maraviroc and maraviroc $1 \%$ gel in HIV-1 seronegative adults; https://clinicaltrials.gov/ct2/show/NCT02346084?term=NCT02346084\&rank=1; last access date January 21, 2019. 